\title{
Synergistic Removal of Humic Acid in Water by Coupling Adsorption and Photocatalytic Degradation Using $\mathrm{TiO}_{2} /$ Coconut Shell Powder Composite
}

\author{
Jong Kyu Kim,, Dae Gyu Jang, ${ }^{2}$ Luiza Cintra Campos, ${ }^{3}$ Yong Wook Jung, \\ Jong-Ho Kim, ${ }^{5}$ and Jin Chul Joo ${ }^{6}$ \\ ${ }^{1}$ Department of Civil Engineering, Kyungnam University, Changwon, Republic of Korea \\ ${ }^{2}$ Department of Construction Environment Engineering, University of Science \& Technology, Daejeon, Republic of Korea \\ ${ }^{3}$ Department of Civil, Environmental and Geomatic Engineering, University College London, London, UK \\ ${ }^{4}$ Advanced Construction Materials Testing Center, Keimyung University, Daegu, Republic of Korea \\ ${ }^{5}$ Department of Chemical Engineering, Chonnam National University, Gwangju, Republic of Korea \\ ${ }^{6}$ Department of Civil and Environmental Engineering, Hanbat National University, Daejeon, Republic of Korea
}

Correspondence should be addressed to Jin Chul Joo; jincjoo@hanbat.ac.kr

Received 27 July 2016; Accepted 6 September 2016

Academic Editor: Rajesh Adhikari

Copyright (c) 2016 Jong Kyu Kim et al. This is an open access article distributed under the Creative Commons Attribution License, which permits unrestricted use, distribution, and reproduction in any medium, provided the original work is properly cited.

\begin{abstract}
The feasibility of applying nanoscale $\mathrm{TiO}_{2} /$ coconut shell powder (TCNSP) composite to remove $\mathrm{HA}$ in aqueous solution was evaluated, and the optimization of the photocatalytic systems using newly developed TCNSP composite was performed. The developed TCNSP composite has high specific surface area (i.e., $454 \mathrm{~m}^{2} / \mathrm{g}$ ) and great porosity (i.e., $66.9 \%$ ) with pore size of less than $5 \mu \mathrm{m}$. High removal efficiencies ( $\geq 95 \%$ ) of HA were observed due to the significant synergistic effects by coupling adsorption and photocatalytic reaction of TCNSP composite. As the initial concentration of HA increased, the degradation rate $\left(K_{\text {app }}\right)$ decreased due to HA sorption saturation to the surface of TCNSP composite and the photon interception by HA molecules in aqueous solution. Since the increased loading amount of TCNSP composite enhanced the number of active sites, $K_{\text {app }}$ values increased until the optimum loading amount of TCNSP composite. As $\mathrm{pH}$ values increased, HA removal efficiency decreased due to increasing electrostatic repulsion between HA and TCNSP composite. Based on the response surface methodology, higher HA removal efficiencies were obtained with acidic condition, longer reaction time, and appropriated loading amount of TCNSP. Further pilotscale study is in progress using TCNSP composite combined with UVC to remove HA from large amounts of surface water (i.e., $200 \mathrm{~m}^{3} / \mathrm{d}$ ).
\end{abstract}

\section{Introduction}

Humic substances are heterogeneous mixtures of polydispersed materials formed by biochemical reactions through both decay and transformation of plant and microbial remains $[1,2]$. Humic substances usually enter the surface waters through rainwater runoff from the surrounding land $[2,3]$ and are also found in the groundwater, aquatic environment, and sewage plant effluents [4]. Humic acid (HA) is a principal component of humic substances, and the presence of HA in drinking water has been reported to produce serious problems, such as undesired color and taste, membrane fouling, biofilm in pipe line, and reduction of the lifetime of granular activated carbon [3]. Moreover, HA can react with chlorine during disinfection processes and produce carcinogenic by-products like trihalomethanes [3].

Conventional treatment processes (i.e., coagulationflocculation, membrane filtration, adsorption, and oxidation) have been widely applied to remove HA in water $[3,5$, 6]. Among various types of treatment processes, heterogeneous photocatalysis using suspended $\mathrm{TiO}_{2}$ or $\mathrm{ZnO}$ particles gained increased attention owing to the potential to degrade recalcitrant organic contaminants in water into nontoxic compounds using highly reactive transitory species 
(e.g., superoxide radical $\left(\mathrm{O}_{2}{ }^{-}\right)$, hydroxyl radical $\left(\mathrm{OH}^{*}\right)$, hydrogen peroxide $\left(\mathrm{H}_{2} \mathrm{O}_{2}\right)$, and singlet oxygen $\left.\left({ }^{1} \mathrm{O}_{2}\right)\right)$ [6-10]. In addition, $\mathrm{TiO}_{2}$ and $\mathrm{ZnO}$ photocatalysts are nontoxic and chemically stable over a wide $\mathrm{pH}$ range [6-10].

Although these nanoscale photocatalysts have great efficiencies in removing recalcitrant organic contaminants, the use of these nanoscale photocatalysts for commercial or industrial applications would require further processes such as separation and recovery. Thus, numerous studies to immobilize these finely powdered photocatalysts on various supports (i.e., activated carbon, charcoal, clay, glass beads, membranes, polymer films, etc.) have been performed [411]. However, several inherent drawbacks resulting directly from the photocatalyst immobilization (i.e., low exposed surface area, mass transfer limitation, and low UV light transmission) still have been reported [8]. Although most drawbacks stemmed from the immobilization techniques between photocatalyst and support, the drawbacks from the photocatalytic system can be overcome through the optimization of the photocatalytic systems via response surface analysis.

In this study, the feasibility of applying nanosized $\mathrm{TiO}_{2} /$ coconut shell powder composite (TCNSP) to remove HA in aqueous solution were evaluated, and the optimization of the photocatalytic systems using TCNSP composite was performed. The specific objectives of this study were (1) to investigate the photocatalytic degradation of $\mathrm{HA}$ in aqueous solution using TCNSP composite, (2) to elucidate the effects of the initial concentration of HA, the loading amount of TCNSP composite, the irradiation source, and the solution $\mathrm{pH}$ on the photocatalytic degradation of HA in aqueous solution, and finally (3) to determine the optimum operation parameters through multivariables optimization approach.

\section{Materials and Methods}

2.1. Composite of Nanoscale $\mathrm{TiO}_{2} /$ Coconut Shell Powder (TCNSP). HA solution was prepared using HA sodium salt (technical grade H16752) obtained from Sigma-Aldrich. All other chemicals used in this study were of analytical grade. The coconut shell powder (CNSP) was purchased from Sri Lanka and contained 58\% holocellulose, 39\% lignin, and 3\% water. The nanoscale $\mathrm{TiO}_{2} /$ coconut shell powder (TCNSP) materials used in this study are exactly the same as those used by Khraisheh et al. [8]. The raw coconut shell powder was washed with deionized water, dried, and crushed with a roller mill (RM2002; Doosan Co. Ltd.) to a diameter of 0.2-0.4 mm. The pretreated coconut shell powder was poured into the water, and the solution was to allow the hydrolysis reaction to take place. Then, the gel was formed and mixed with $\mathrm{TiO}_{2}$ nanoparticles. Finally, a semiautomated mass production line (i.e., kneading, roller compaction, pelletization, and mechanofusion processes) was used as the granulation. The detail information for synthesis and characterization of the TCNSP composites are described by Khraisheh et al. [8].

2.2. Preparation of HA Solution. HA stock solution was prepared by dissolving $100 \mathrm{mg}$ of HA powder in $1 \mathrm{~L}$ of Millipore

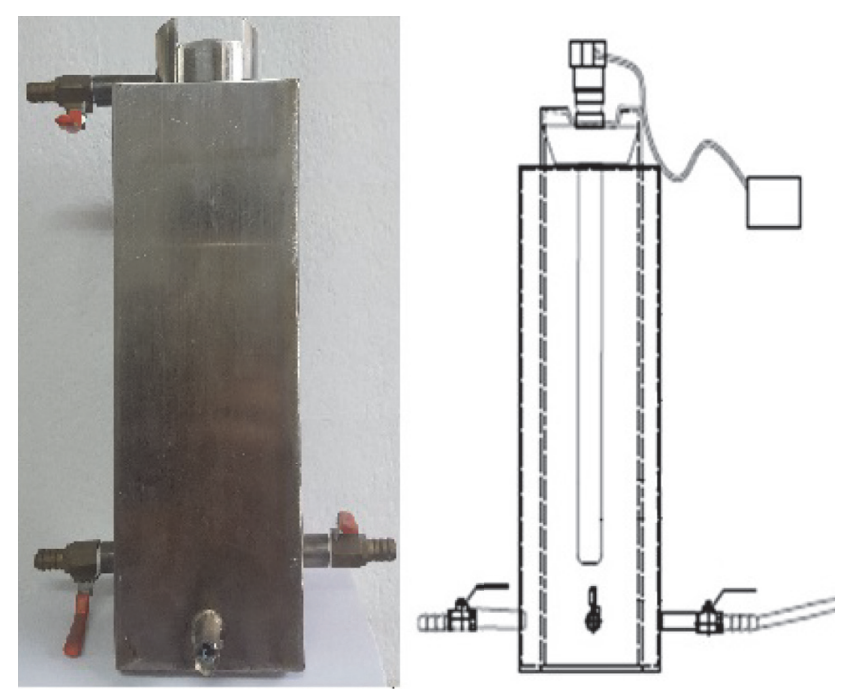

FIgURE 1: Pictorial view and schematic cross-sectional diagram of photocatalytic reactor.

water. The solution was mixed using a magnetic stirrer to ensure that the HA was completely dissolved in Millipore water, and the HA stock solution was stored at $4^{\circ} \mathrm{C}$ before the experiment. The solutions for all adsorption and photocatalytic reaction tests were prepared by adding the HA stock solution to Millipore water to achieve the desired HA concentrations.

2.3. Analytical Methods. Concentration changes in HA during the adsorption and photocatalytic reaction tests were observed using high performance liquid chromatography (HPLC) system (Perkin Elmer Inc., UK) with series of pumps and an auto sampler, and a UV/Vis detector was operated at a wavelength of $254 \mathrm{~nm}\left(\mathrm{UV}_{254}\right)$ using the TotalChrom software (PerkinElmer, USA). Although $\mathrm{UV}_{254}$ has been widely used to measure the photocatalytic degradation of HA, some of intermediate oxidation products of HA do not absorb $\mathrm{UV}_{254}$. Thus, concentration changes in total organic carbon (TOC) during the adsorption and photocatalytic reaction tests were also observed using TOC analyzers (Shimadzu Co., Japan) adopting the $680^{\circ} \mathrm{C}$ combustion catalytic oxidation method.

2.4. Batch Adsorption and Photocatalytic Degradation Tests. Both adsorption and photocatalytic degradation of HA were performed in a batch adsorption and photocatalysis reactor which was used in previous study [6]. The batch adsorption and photocatalysis reactor consists of rectangular box employing a UV lamp mounted vertically inside the reactor, and all parts were made with stainless steel to suppress the reactions between HA and surface of the reactor (Figure 1). In all experiments, to enhance the mixing, aeration was provided by supplying air to the system at a flow rate of $0.001 \mathrm{~L} / \mathrm{min}$ using an air flow meter (CT Platon Model). Both temperature control and cooling bath were supplied to 

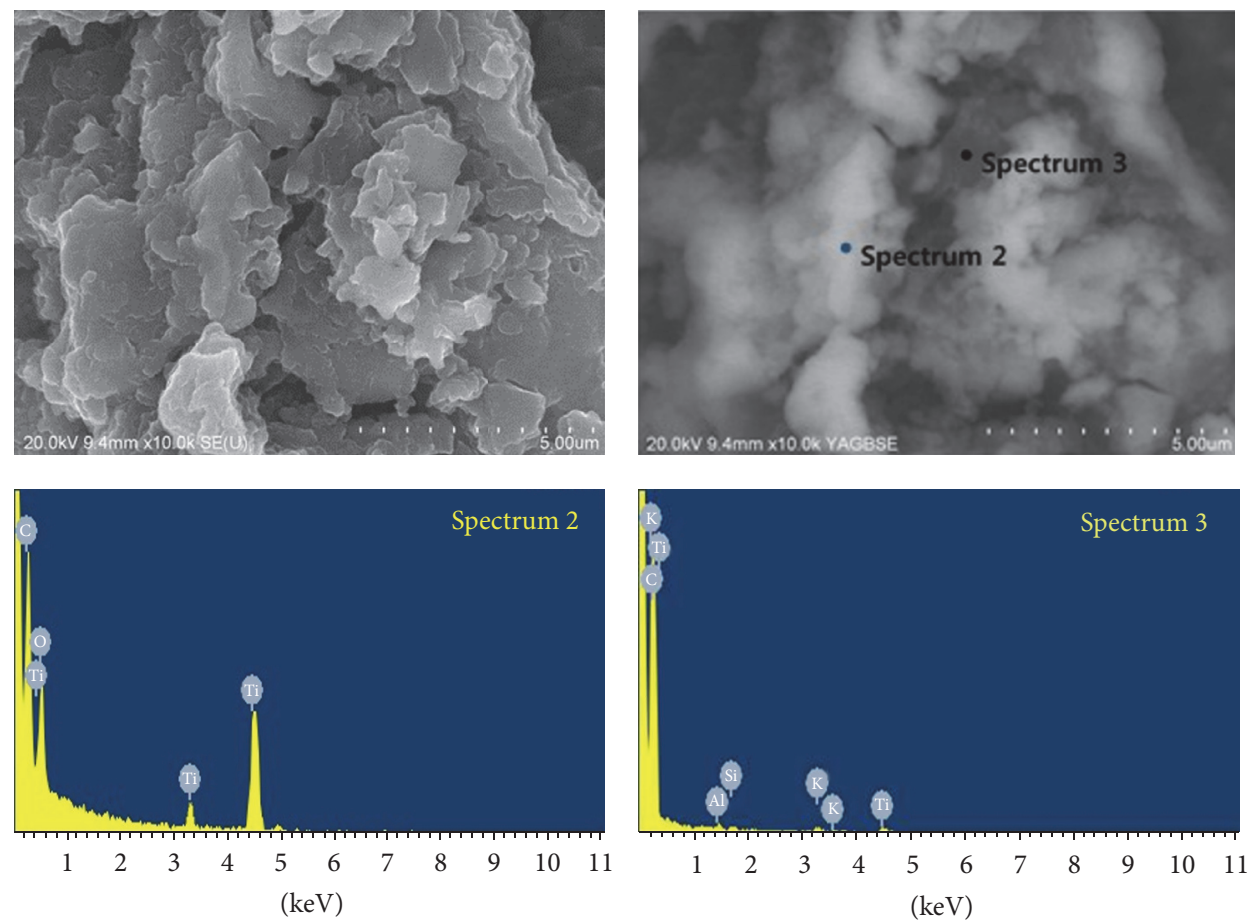

Full scale 744 cts cursor: 0.000

Full scale 975 cts cursor: 0.000

FIGURE 2: Scanning electron microscopy/energy dispersive X-ray spectroscopy (SEM/EDS) of TCNSP.

prevent the lamps from overheating the HA solution; hence, the temperature was maintained between $18-22^{\circ} \mathrm{C}$.

All experiments were performed in triplicate using $\mathrm{HA}$ solutions with different initial concentrations of $\mathrm{HA}$ and different loading amounts of TCNSP composites during a reaction period of $60 \mathrm{~min}$ based on preliminary study [6]. To evaluate the effect of light wavelength, two types of UV light sources (i.e., UVC lamp (Philips, Holland) with a principal output at $254 \mathrm{~nm}$ and UVA lamp (Philips, Holland) with a principal output at $365 \mathrm{~nm}$ ) were used. To elucidate the effect of solution $\mathrm{pH}$ on photocatalytic degradation of HA in the aqueous phase, different $\mathrm{pH}$ values (i.e., 4.0, 7.0, and 10.0) were titrated by adding $0.1-\mathrm{M} \mathrm{HCl}$ or $0.1-\mathrm{M} \mathrm{NaOH}$.

2.5. Response Surface Methodology (RSM) Analysis. To determine the optimal configurations of HA removal using TCNSP composites, the response surface methodology (RSM) was used as one of the most effective tools for the design of experiments [12]. In this study, three independent (variable) factors were chosen to compose the central composite design (CCD) matrix, and the residual concentration of $\mathrm{HA}\left(\mathrm{RC}_{\mathrm{HA}}\right)$ was selected as the response factor (dependent variable) against the three combined factors. Codified values were used for low $(-1)$, center $(0)$, high $(+1)$, and axial $( \pm \alpha)$ points which were included in the matrix to estimate the curvature of the model. In addition, the standard error of the variable was the same as in any point of the mounted surface [13].

In total 19 tests were set up for this study, with eight factorial points $\left(2^{3}\right)$ helping to define cube boundaries, six repetitions of the center point to allow for a test model lack of the fit model test, and six axial points $( \pm \alpha)$ to define the model's curvature. Three effective parameters, including loading amount of TCNSP, $\mathrm{pH}$ of solution, and reaction time, were selected to design the experiments. Experimental results were arranged according to the design, and the programme of design was operated with statistical and graphical software Minitab version 16 (State College, PA, USA).

\section{Results and Discussion}

3.1. Characterization of Nanoscale $\mathrm{TiO}_{2} /$ Coconut Shell Powder (TCNSP) Composite. Scanning electron microscopy images and energy dispersive X-ray spectroscopy (EDS) spectrum of the newly developed TCNSP are presented in Figure 2. As shown in Figure 2, the nanoscale $\mathrm{TiO}_{2}$ particles are well dispersed on the surface of coconut shell char particles, and the TCNSP has various types of porosity less than $5 \mu \mathrm{m}$. As described by Khraisheh et al. [8], the elemental composition of TCNSP composite is $58.9 \%$ of C, $25.6 \%$ of O, and $15.5 \%$ of $\mathrm{Ti}$ at the spectrum 2 point and $37.2 \%$ of $\mathrm{C}, 22.7 \%$ of $\mathrm{Ti}$, 39.5 of $\mathrm{K}$ with the rests (i.e., $\mathrm{Al}, \mathrm{Si}$ ) at the spectrum 3 point, respectively. The detail porosity characteristics of TCNSP are summarized in Table 1.

3.2. Removal of HA by Coupling Adsorption and Photocatalytic Activity of TCNSP Composite. To investigate the photolysis, adsorption, and photocatalysis' properties of the TCNSP composite, various batch tests (i.e., HA solution with only UVC lamp, HA solution with only TCNSP composite, and HA solution with both UVC lamp and TCNSP composite) 
TABLE 1: Porosity characterization of TCNSP.

\begin{tabular}{lcccc}
\hline BET $^{\mathrm{a}}\left(\mathrm{m}^{2} / \mathrm{g}\right)$ & Crush strength $^{\mathrm{b}}(\mathrm{N} /$ granule $)$ & Pore volume $^{\mathrm{a}}\left(\mathrm{cm}^{3} / \mathrm{g}\right)$ & Pore $^{\text {size }}(\mathrm{nm})$ & Porosity $^{\mathrm{a}}(\%)$ \\
\hline 454 & $25.7 \pm 3.4$ & 0.24 & 2.2 & 66.87 \\
\hline
\end{tabular}

${ }^{a}$ Brunauer-Emmett-Teller.

${ }^{\mathrm{b}}$ ASTM E8 using universal testing machine.

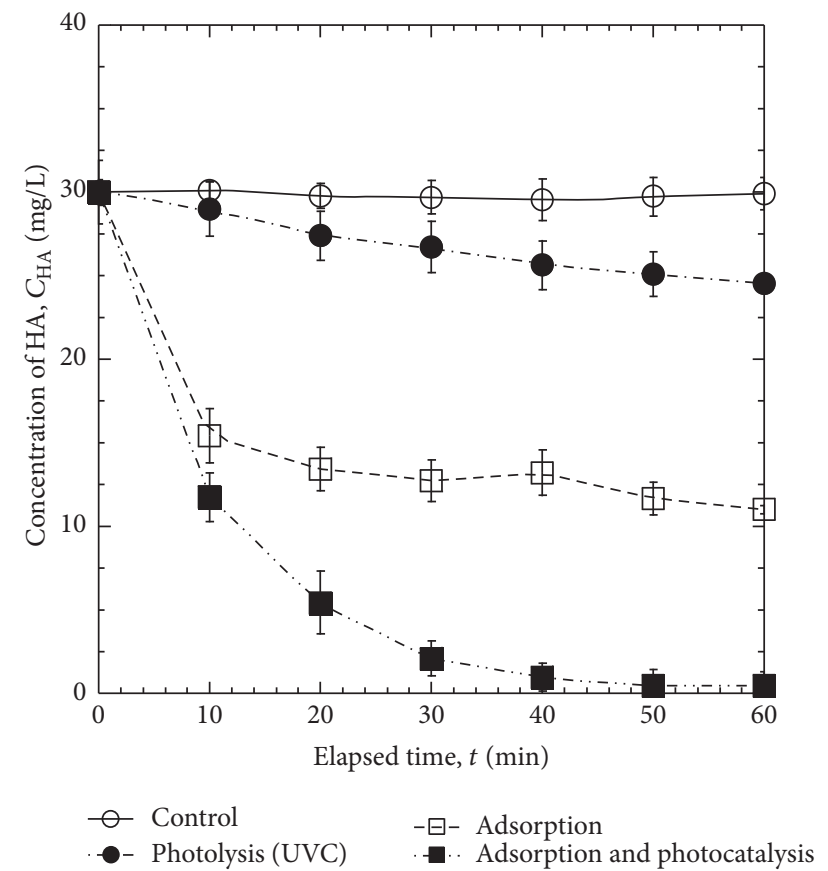

FIGURE 3: Removal of HA in aqueous solution under different conditions at $\mathrm{pH} 7$ and $30 \mathrm{mg} / \mathrm{L}$ initial HA concentration (only HA solution (control), HA solution with UVC lamp (photolysis), HA solution with $20 \mathrm{~g} / \mathrm{L}$ of TCNSP (adsorption), and HA solution with $20 \mathrm{~g} / \mathrm{L}$ of TCNSP and UVC lamp (adsorption \& photocatalysis)).

were conducted, and results are shown in Figure 3. Negligible concentration changes in the control (i.e., $C / C_{0}=0.98-1.01$ ) were observed, indicating that the attachment of $\mathrm{HA}$ to the batch photocatalytic reactor was found to be insignificant.

Photolysis and adsorption tests for HA removal resulted in around $19 \%$ and $61 \%$ of removal efficiencies, respectively, after the $60 \mathrm{~min}$ reaction time (Figure 3). The adsorption of HA onto the surface of TCNSP composite approached equilibrium after $20 \mathrm{~min}$ of reaction time. Consistent with other studies $[8,14]$, the great adsorption of $\mathrm{HA}$ by the TCNSP composite can be explained by its high-surface-area $\left(\mathrm{BET}=454 \mathrm{~m}^{2} / \mathrm{g}\right)$ TCNSP composite. During the calcination process, the holocellulose, cellulose, and lignin in CNSP were polymerized, and hence lots of pores and channels were observed, contributing to enhanced HA adsorption onto TCNSP composite [15].

The removal efficiency of HA under photocatalysis experiment was larger than $95 \%$ within $40 \mathrm{~min}$, indicating that significant synergistic effects by coupling adsorption and photocatalytic reaction of TCNSP composite occurred. These results are mainly attributed to both the photolysis and

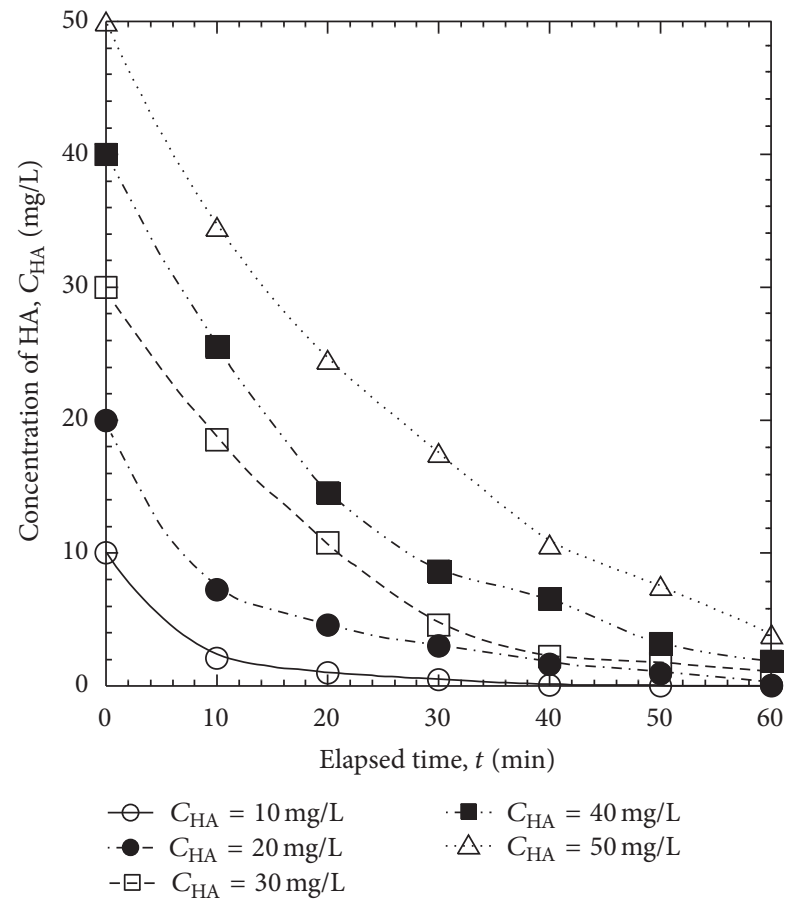

FIGURE 4: Effect of initial concentration of HA on the photocatalytic degradation (loading amount of TCNSP $=20 \mathrm{~g} / \mathrm{L}$, light source $=$ $8.4 \mathrm{~mW} / \mathrm{cm}^{2}$ of $\mathrm{UVC}$, and $\mathrm{pH}=7$ ).

photocatalysis by direct reaction with photons and indirection reaction with $\mathrm{OH}$ radicals coupled with adsorption of HA onto the surface of TCNSP composite.

Compared to the synthesized photocatalyst composite using $\mathrm{ZnO}$ particles with inorganic supports (i.e., NZLC) developed by Kim et al. [6], the synthesized photocatalyst composite using $\mathrm{TiO}_{2}$ particles with organic supports (i.e., TCNSP) resulted in increased removal efficiency of complex $\mathrm{HA}$ and intermediate oxidation products in aqueous solution. The removal efficiency of $\mathrm{HA}$ using nano- $\mathrm{ZnO} /$ laponite composite (NZCL) under UVC irradiation was 91\% [6], while the removal of HA using TCNSP composite was enhanced.

3.3. Effect of Initial Concentration of HA. In terms of both mechanistic and engineering performance perspectives, the dependence of adsorption and photocatalytic reaction rate on the HA concentration needs to be elucidated. Thus, the effect of HA concentration on the degradation rate was examined at different initial HA concentrations varying from 10 to $50 \mathrm{mg} / \mathrm{L}$ under UVC irradiation. As shown in Figure 4, 99\% of HA were removed at $40 \mathrm{~min}$ for initial concentrations of $10 \mathrm{mg} / \mathrm{L}$ whereas only $78 \%$ of HA were removed for initial 
TABLE 2: Summary of apparent first-order degradation rate constant $\left(K_{\mathrm{app}}\right)$ of HA under various conditions.

\begin{tabular}{|c|c|c|c|c|c|}
\hline Run & $C_{0}{ }^{a}(\mathrm{mg} / \mathrm{L})$ & Loading amount of TCNSP $(\mathrm{g} / \mathrm{L})$ & $\mathrm{pH}^{\mathrm{b}}$ & Type of lamp & $K_{\text {app }}{ }^{\mathrm{c}}\left(\min ^{-1}\right)$ \\
\hline \multicolumn{6}{|c|}{ Effect of initial concentration } \\
\hline 1 & 10 & 20 & 9 & UVC & 0.1091 \\
\hline 2 & 20 & 20 & 9 & UVC & 0.0749 \\
\hline 3 & 30 & 20 & 9 & UVC & 0.0588 \\
\hline 4 & 40 & 20 & 9 & UVC & 0.0505 \\
\hline 5 & 50 & 20 & 9 & UVC & 0.0413 \\
\hline \multicolumn{6}{|c|}{ Effect of loading amount for TCNSP } \\
\hline 6 & 30 & 2 & 9 & UVC & 0.0173 \\
\hline 7 & 30 & 10 & 9 & UVC & 0.0327 \\
\hline 8 & 30 & 20 & 9 & UVC & 0.0588 \\
\hline 9 & 30 & 40 & 9 & UVC & 0.0539 \\
\hline 10 & 30 & 60 & 9 & UVC & 0.0593 \\
\hline \multicolumn{6}{|c|}{ Effect of irradiation source } \\
\hline 11 & 30 & 20 & 9 & $U_{V C}{ }^{d}$ & 0.0588 \\
\hline 12 & 30 & 20 & 9 & $\mathrm{UVA}^{\mathrm{e}}$ & 0.0219 \\
\hline 13 & 30 & 0 & 9 & UVC & 0.0034 \\
\hline 14 & 30 & 0 & 9 & UVA & 0.0015 \\
\hline \multicolumn{6}{|c|}{ Effect of $\mathrm{pH}$} \\
\hline 15 & 30 & 20 & 3 & UVC & 0.1043 \\
\hline 16 & 30 & 20 & 5 & UVC & 0.0961 \\
\hline 17 & 30 & 20 & 7 & UVC & 0.0588 \\
\hline 18 & 30 & 20 & 9 & UVC & 0.0447 \\
\hline 19 & 30 & 20 & 11 & UVC & 0.0341 \\
\hline
\end{tabular}

${ }^{\mathrm{a}}$ Initial concentration of HA.

${ }^{\mathrm{b}} \mathrm{pH}$ was adjusted as a constant with minimal errors $( \pm 0.2)$ throughout the whole experiments.

${ }^{c}$ Apparent or lumped first-order degradation rate constant.

${ }^{\mathrm{d}}$ Ultraviolet C (254 $\left.\mathrm{nm}\right)$.

${ }^{\mathrm{e}}$ Ultraviolet A (365 nm).

concentrations of $50 \mathrm{mg} / \mathrm{L}$, indicating that the degradation rate decreased as the initial concentration of HA increased (see Figure 4 and Table 2).

As the initial concentration of HA increased, the pores of the TCNSP composite surface gradually reached HA saturation and resulted in decreased adsorption of HA. Furthermore, the photons generated from UV light were intercepted by the HA molecules in aqueous solution before the photons reaching the TCNSP surface. Considering that the creation of intermediate oxidation products also affect the degradation rate of HA, a higher HA concentration could yield a higher concentration of adsorbed intermediates with low molecular weight, which also decrease the overall degradation rate.

Figure 5 shows the comparison of the apparent firstorder rate constant $\left(K_{\text {app }}\right)$ values between TCNSP composite and NZLC [6] as a function of initial concentration of HA. Whereas the $K_{\text {app }}$ values of NZLC increased with increasing HA concentration from $10 \mathrm{mg} / \mathrm{L}$ to $20 \mathrm{mg} / \mathrm{L}$ and then remained constant for 30,40 , and $50 \mathrm{mg} / \mathrm{L}$ of HA, the $K_{\text {app }}$ values of TCNSP composite decreased as the initial concentration of HA increased from 10 to $50 \mathrm{mg} / \mathrm{L}$. Overall, $K_{\text {app }}$ values of TCNSP were greater than those of NZLC for all HA concentrations. This was probably due to the fact that

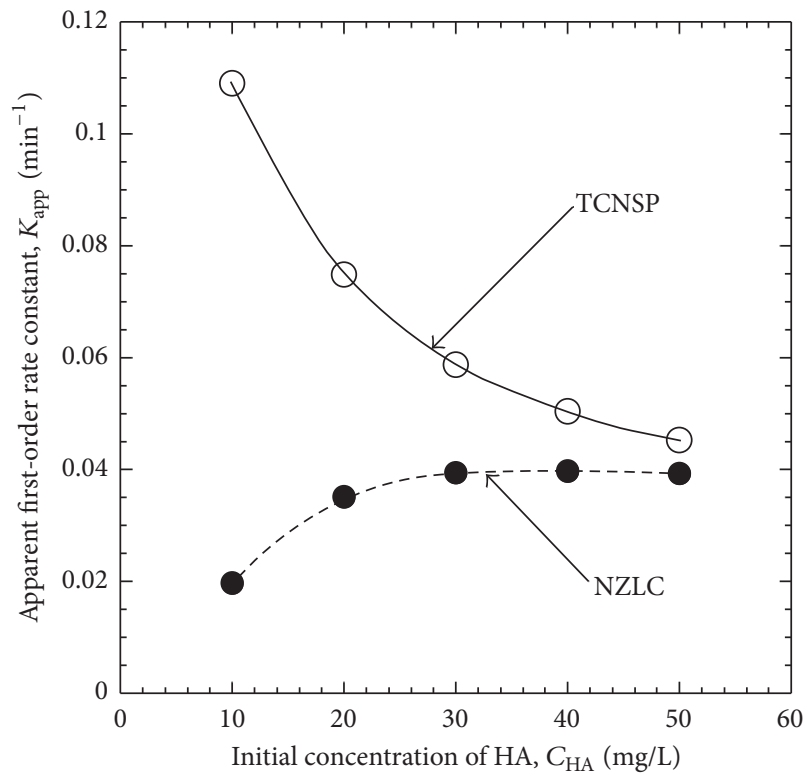

FIGURE 5: Comparison of the apparent first-order degradation rate constant $\left(K_{\text {app }}\right)$ values between TCNSP composite and NZLC (loading amount of TCNSP \& NZLC $=20 \mathrm{~g} / \mathrm{L}$ and light source $=$ $8.4 \mathrm{~mW} / \mathrm{cm}^{2}$ of UVC) ( $K_{\text {app }}$ values of NZLC extracted from [6]). 


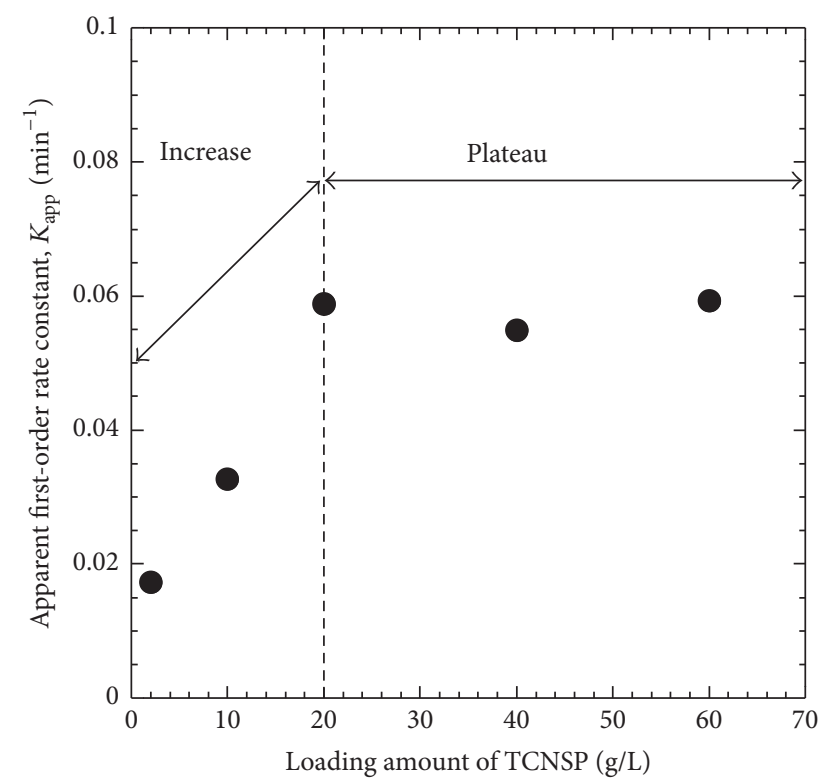

FIGURE 6: Effect of loading amount of TCNSP composite on the degradation rate of $\mathrm{HA}$ (initial concentration of $\mathrm{HA}=30 \mathrm{mg} / \mathrm{L}$, light source $=8.4 \mathrm{~mW} / \mathrm{cm}^{2}$ of $\mathrm{UVC}$, and $\mathrm{pH}=7$ ).

TCNSP composite has high number of active sites available for both adsorption and photocatalytic degradation of HA than NZLC. Therefore, these results indicate that TCNSP composite could remove HA from water more efficiently than NZLC.

3.4. Effect of Loading Amount of TCNSP Composite. The effect of different loading amounts of TCNSP composite on the photocatalytic degradation for HA was investigated in the range of 2 to $60 \mathrm{~g} / \mathrm{L}$. The relationship between the $K_{\text {app }}$ values and the loading amount of TCNSP composite after a reaction period of $60 \mathrm{~min}$ is shown in Figure 6 and Table 2. The experimental results indicate an increase in $K_{\text {app }}$ values from 0.0173 to 0.0588 as the loading amount of TCNSP composite increased from 2 to $20 \mathrm{~g} / \mathrm{L}$. However, for the increased loading amount of TCNSP composite from 20 to $60 \mathrm{~g} / \mathrm{L}$, the $K_{\text {app }}$ values were not affected, indicating that loading amount of TCNSP composite reached a certain critical value.

Since the increased loading amount of TCNSP composite enhanced the number of active sites that were available for the adsorption and photocatalysis, $K_{\text {app }}$ values increased. However, greater loading amount of TCNSP composite over the optimum loading amount did not improve HA degradation due to the block of UV light scattering, resulting in reduced photocatalytic degradation. Therefore, loading amount of TCNSP composite can be one of the critical design parameters for photocatalytic degradation process of HA in practical application [8].

3.5. Effect of Irradiation Source. Degradation rate of HA increased in the following order as UVC/TCNSP > UVA/ TCNSP $>$ UVC > UVA (see Figure 7). The degradation rate

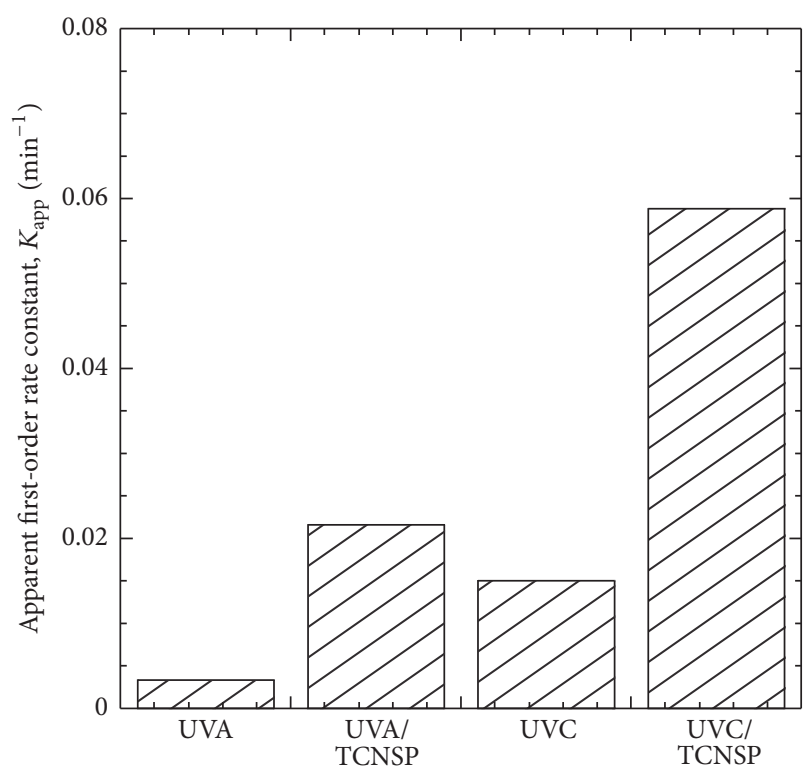

FIGURE 7: Effect of irradiation source on the degradation of HA (initial concentration of $\mathrm{HA}=30 \mathrm{mg} / \mathrm{L}, \mathrm{pH}=9 \pm 0.2$, and loading amount of TCNSP $=20 \mathrm{~g} / \mathrm{L}$ ).

$\left(0.0015 \mathrm{~min}^{-1}\right)$ under the illumination of UVA in the absence of TCNSP composite was low, whereas the degradation rate $\left(0.0034 \mathrm{~min}^{-1}\right)$ increased twice under the illumination of UVC light in the absence of TCNSP composite. These results were mainly attributed to the phenomenon that a greater number of photons were generated from a small fraction of UVC at $254 \mathrm{~nm}$ wavelength with higher photonic energy [16].

In addition, degradation rate in the presence of TCNSP significantly increased to $0.0219 \mathrm{~min}^{-1}$ at UVA and $0.0588 \mathrm{~min}^{-1}$ at UVC, respectively. This was probably due to the fact that the presence of $\mathrm{TiO}_{2}$ on the surface of TCNSP created more radicals generated from UV light source, resulting in a dramatically increased HA removal efficiency. This result is consistent with Khraisheh et al. [8] who postulated a faster and greater degradation of organic contaminants in the presence of $\mathrm{TiO}_{2}$ combined with UVA and/or UVC irradiation, compared to reactions with sole UVA or UVC irradiation.

3.6. Effect of $p H$. The photocatalytic degradation of HA using the TCNSP composite with UVC irradiation was examined at different $\mathrm{pH}$ values $(3,5,7,9$, and 11). As shown in Figure 8 and Table 2, the $K_{\text {app }}$ values gradually decreased with increasing $\mathrm{pH}$ value reaching a value of $0.0341 \mathrm{~min}^{-1}$ at $\mathrm{pH} 11$. Also, the HA removal efficiencies were over $96 \%$ between $\mathrm{pH} 3$ and 7 and decreased to around $88 \%$ at $\mathrm{pH} 11$. At higher $\mathrm{pH}$, the carboxyl and phenolic groups of HA were dissociated and suppressed adsorption of HA occurred from pores on the TCNSP composite, causing a gradual decrease in the degradation of HA [17].

Considering that the point of zero charge $\left(\mathrm{pH}_{\mathrm{pzc}}\right)$ of the $\mathrm{TiO}_{2}$ (Degussa P25) is well known as $6.25[18,19]$, the surface 


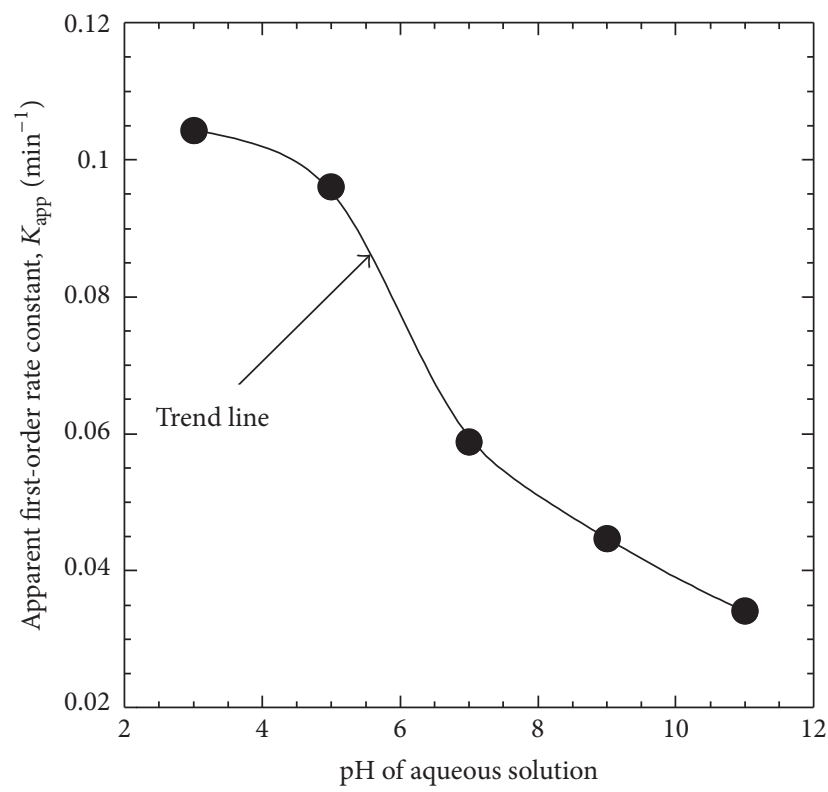

FIGURE 8: Effect of $\mathrm{pH}$ in aqueous solution on the degradation rate of $\mathrm{HA}$ (initial concentration of $\mathrm{HA}=30 \mathrm{mg} / \mathrm{L}$, light source $=$ $8.4 \mathrm{~mW} / \mathrm{cm}^{2}$ of $\mathrm{UVC}$, and $\mathrm{pH}=7$ ).

of $\mathrm{TiO}_{2}$ becomes a net positive charge as $\mathrm{pH}$ decreases below the $\mathrm{pH}_{\mathrm{pzc}}(\mathrm{pH}<6.25)$ and a net negative charge as $\mathrm{pH}$ increases over the $\mathrm{pH}_{\mathrm{pzc}}(\mathrm{pH}>6.25)$. On the other hand, the $\mathrm{pH}_{\mathrm{pzc}}$ of HA is very low, around 0.5 [20]. As a result, both adsorption and electrostatic attractions occurred between the $\mathrm{TiO}_{2}$ on the surface of TCNSP composite, and HA removal increased as $\mathrm{pH}$ values decreased. However, as $\mathrm{pH}$ values increased, adsorption efficiency of TCNSP composite decreased due to increasing electrostatic repulsion between HA and TCNSP composite.

3.7. Reuse Tests of TCNSP Composites and NZLC. The changes in HA removal efficiency after reuse tests with TCNSP and NZLC [6] are shown in Figure 9. After the first $60 \mathrm{~min}$ degradation reaction, both composites were separated and reused for further runs without any treatment. After six runs, TCNSP composite was still efficiently reused with 93\% of HA removal, whereas removal efficiency of NZLC decreased dramatically with approximately only $57 \%$ of HA removal.

These differences can be mainly attributed to the fact that NZLC had smaller specific surface area (i.e., $120 \mathrm{~m}^{2} / \mathrm{g}$ ) and pore volume (i.e., $0.1 \mathrm{~cm}^{3} / \mathrm{g}$ ) than TCNSP composite, hence limiting the ability of adsorbing HA molecules. Consequently, NZLC reached its break point faster than TCNSP composite. After several runs, both adsorption and photocatalytic ability of NZLC were significantly reduced, resulting in decreased removal efficiency. Also, $\mathrm{TiO}_{2}$ particles in TCNSP composite showed better photocatalytic activity than $\mathrm{ZnO}$ particles in NZLC. Thus, adsorption capacity of TCNSP is continuously recovered so that the removal efficiency of HA was preserved at high level after several runs [8].

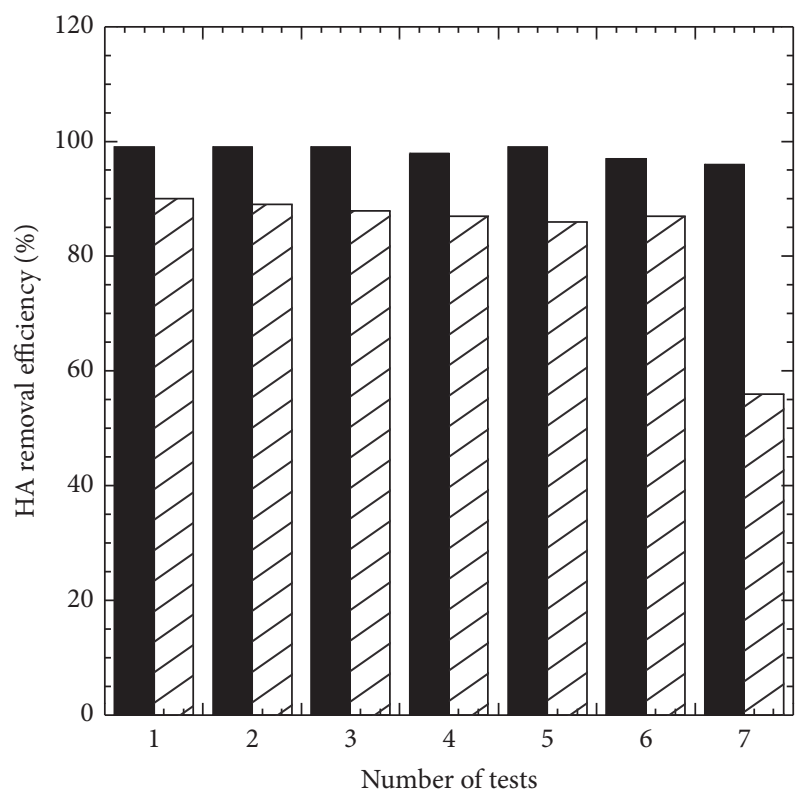

TCNSP

NZLC

FIgURE 9: Reuse test for removal of HA with TCNSP and NZLC (initial concentration of $\mathrm{HA}=30 \mathrm{mg} / \mathrm{L}$, loading amount of catalyst $=20 \mathrm{~g} / \mathrm{L}$, light source $=8.4 \mathrm{~mW} / \mathrm{cm}^{2}$ of UVC, and $\mathrm{pH}=7$ ).

3.8. Optimization of Operation Parameters for HA Removal. The proposed CCD matrix was tested to analyze and compare the effects of $\mathrm{pH}$, loading amount of TCNSP, and reaction time for HA removal. As displayed in (1), the model representing the remaining HA concentration $(Y)$ was expressed as functions of $\mathrm{pH}\left(x_{1}\right)$, TCNSP loading amount $\left(x_{2}\right)$, and reaction time $\left(x_{3}\right)$ for coded units. Coded and actual levels of variables with experimental and predicted results are summarized in Table 3, and the response surface cubic model was obtained by (1).

$$
\begin{aligned}
Y= & 36.453-0.505 x_{1}-0.867 x_{2}-0.771 x_{3} \\
& -0.003 x_{1} x_{2}+0.001 x_{1} x_{3}-0.001 x_{2} x_{3}+0.091 x_{1}^{2} \\
& +0.011 x_{2}^{2}+0.008 x_{3}^{2} .
\end{aligned}
$$

To obtain better understanding of the remaining concentration of HA, the predicted models are presented in Figures 10-12 as contour plots. Figure 10 displayed the contour plot relationship between $\mathrm{pH}$ and TCNSP loading amount on remaining concentration of HA. Higher HA removal efficiencies were achieved with higher amounts of TCNSP and lower $\mathrm{pH}$ values (Figure 10). The optimal values of TCNSP amount were observed at the range of $30-50 \mathrm{~g}$, while the optimal values of $\mathrm{pH}$ were gained at the range of 2-6. These results indicated that better HA removal efficiencies can be achieved in acid condition and with appropriated loading amount of TCNSP.

The interaction between reaction time and $\mathrm{pH}$ plotted against a constant TCNSP amount at $30 \mathrm{~g}$ indicated that 
TABLE 3: Coded and actual levels of variables with experimental and predicted results.

\begin{tabular}{|c|c|c|c|c|c|c|c|c|}
\hline \multirow{2}{*}{ Run } & \multicolumn{2}{|c|}{$\mathrm{pH}$} & \multicolumn{2}{|c|}{ TCNSP (g) } & \multicolumn{2}{|c|}{ Time (min) } & \multicolumn{2}{|c|}{ Remaining concentration $(\mathrm{mg} / \mathrm{L})$} \\
\hline & Coded value & Actual value & Coded value & Actual value & Coded value & Actual value & Experimental & Predicted \\
\hline $\mathrm{R} 1$ & $(-1)$ & 3 & (1) & 50 & (1) & 50 & 2.01 & 0.07 \\
\hline $\mathrm{R} 2$ & $(-1)$ & 3 & $(1)$ & 50 & $(-1)$ & 10 & 15.24 & 12.24 \\
\hline $\mathrm{R} 3$ & $(1)$ & 11 & $(-1)$ & 10 & $(1)$ & 50 & 17.45 & 16.98 \\
\hline $\mathrm{R} 4$ & $(0)$ & 7 & $(0)$ & 30 & $(0)$ & 30 & 4.55 & 4.41 \\
\hline R5 & $(0)$ & 7 & $(-\alpha)$ & 2 & $(0)$ & 30 & 26.54 & 25.76 \\
\hline R6 & (1) & 11 & $(1)$ & 50 & (1) & 50 & 9.54 & 5.06 \\
\hline R7 & (0) & 7 & $(0)$ & 30 & $(0)$ & 30 & 4.56 & 4.41 \\
\hline $\mathrm{R} 8$ & $(\alpha)$ & 13 & $(0)$ & 30 & $(0)$ & 30 & 9.15 & 13.09 \\
\hline R9 & (0) & 7 & $(0)$ & 30 & $(0)$ & 30 & 4.61 & 4.41 \\
\hline R10 & (0) & 7 & (0) & 30 & $(0)$ & 30 & 4.48 & 4.41 \\
\hline R11 & (0) & 7 & $(0)$ & 30 & $(0)$ & 30 & 4.55 & 4.41 \\
\hline $\mathrm{R} 12$ & (1) & 11 & $(-1)$ & 10 & $(-1)$ & 10 & 28.58 & 27.05 \\
\hline $\mathrm{R} 13$ & $(0)$ & 7 & $(0)$ & 30 & $(-\alpha)$ & 2 & 21.35 & 23.54 \\
\hline R14 & $(-1)$ & 3 & $(-1)$ & 10 & $(-1)$ & 10 & 20.14 & 21.15 \\
\hline R15 & $(-\alpha)$ & 1 & $(0)$ & 30 & $(0)$ & 30 & 2.98 & 3.94 \\
\hline R16 & $(-1)$ & 3 & $(-1)$ & 10 & (1) & 50 & 11.24 & 10.73 \\
\hline $\mathrm{R} 17$ & (1) & 11 & $(1)$ & 50 & $(-1)$ & 10 & 19.85 & 16.88 \\
\hline $\mathrm{R} 18$ & (0) & 7 & $(0)$ & 30 & $(0)$ & 30 & 4.56 & 4.41 \\
\hline R19 & (0) & 7 & $(\alpha)$ & 30 & $(0)$ & 30 & 2.55 & 8.24 \\
\hline $\mathrm{R} 20$ & $(0)$ & 7 & $(0)$ & 30 & $(\alpha)$ & 60 & 2.11 & 4.83 \\
\hline
\end{tabular}
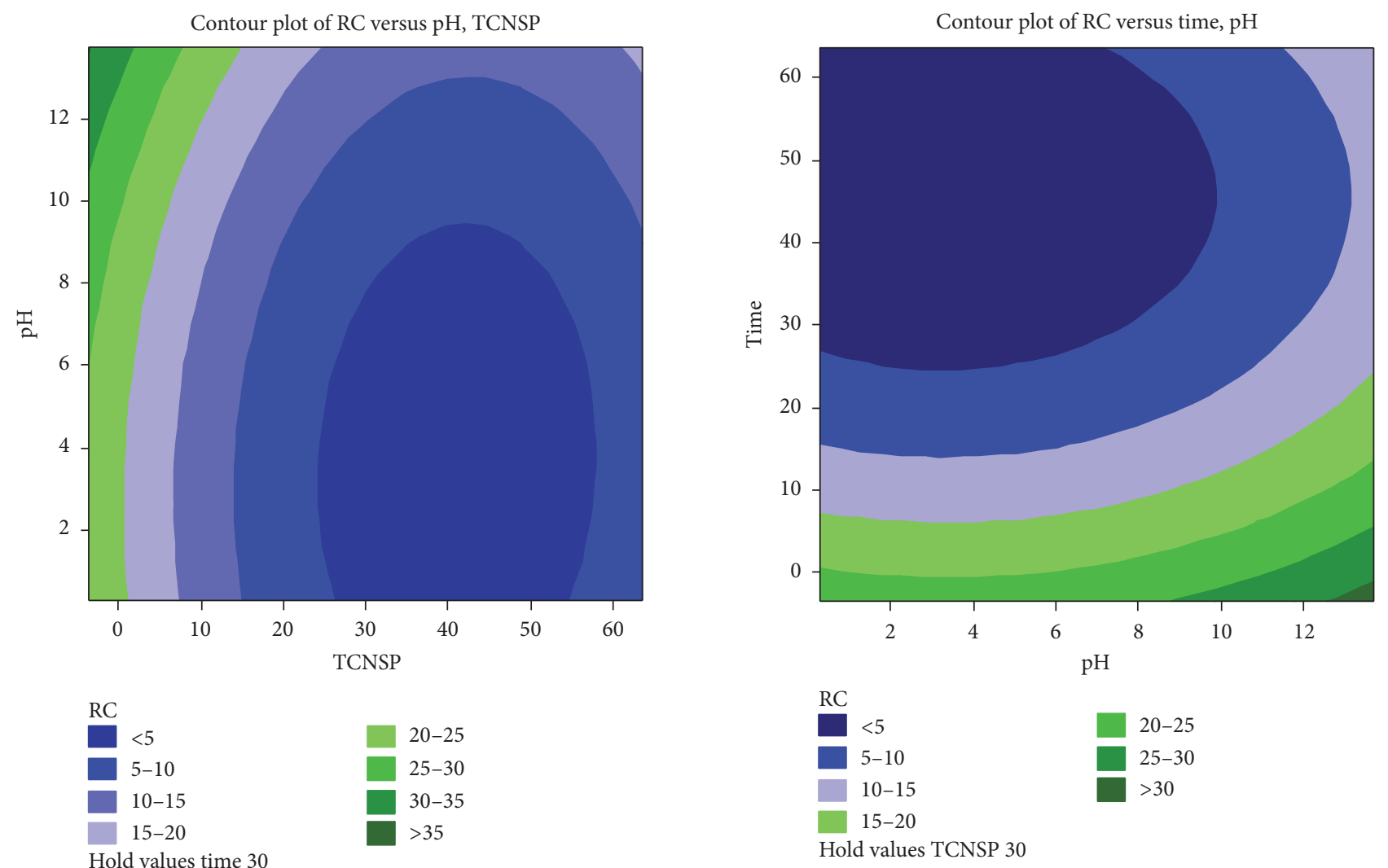

FIGURE 10: Contour plot of HA remaining concentration as the function of $\mathrm{pH}$ and TCNSP loading amount $(\mathrm{g})$.

FIgURE 11: Contour plot of HA remaining concentration as the function of reaction time $(\mathrm{min})$ and $\mathrm{pH}$. 


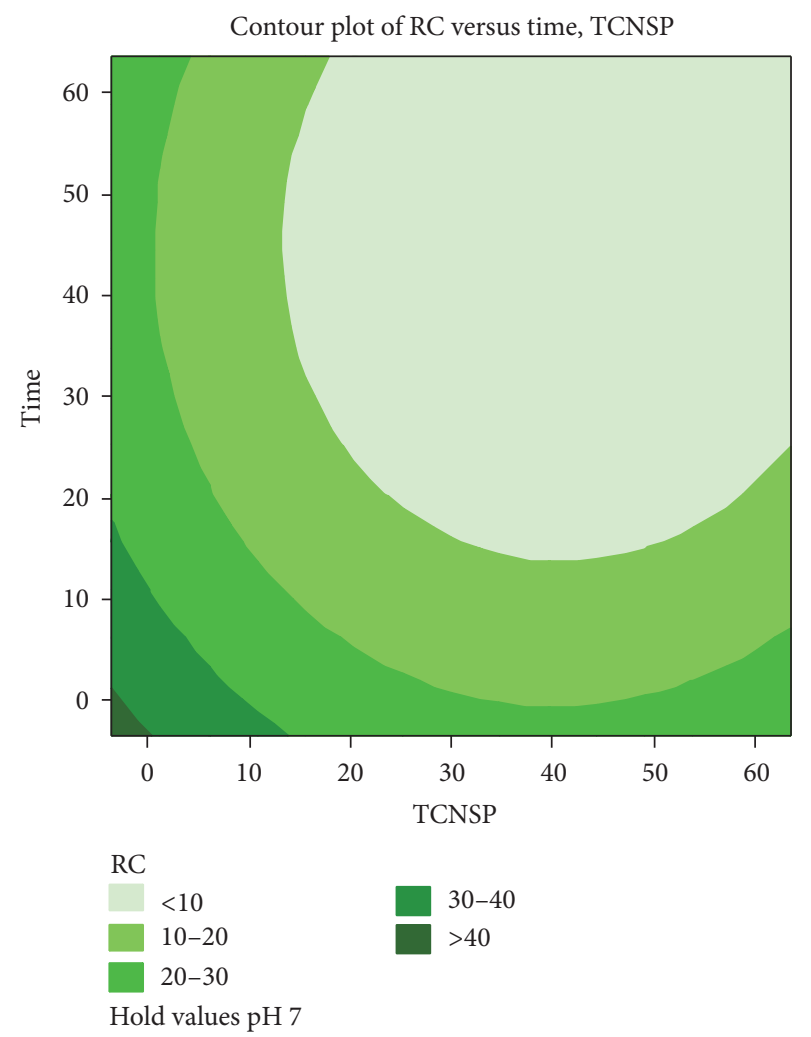

FIgURE 12: Contour plot of HA remaining concentration as the function of reaction time (min) and TCNSP loading amount $(\mathrm{g})$.

higher removal efficiencies were observed after $30 \mathrm{~min}$ of reaction time and lower $\mathrm{pH}$ ranges (Figure 11). Figure 12 shows the relationship between reaction time and TCNSP loading amount at constant $\mathrm{pH}$ 7. Higher removal efficiencies were achieved with longer reaction time and increasing TCNSP loading amounts (Figure 12). Based on these contour plot results, higher HA removal efficiencies were obtained with acidic condition, longer reaction time, and appropriated loading amount of TCNSP. Based on the critical values prediction tools, the optimal values of operation parameters were found to be 3.75 for $\mathrm{pH}, 47.43 \mathrm{~g}$ for TCNSP loading amount, and $34.12 \mathrm{~min}$ for reaction time, respectively.

\section{Conclusions}

The feasibility of applying nanoscale $\mathrm{TiO}_{2} /$ coconut shell powder (TCNSP) composite to remove $\mathrm{HA}$ in aqueous solution was evaluated, and the optimization of the photocatalytic systems using TCNSP composite was also investigated. Newly developed TCNSP composite synthesized via the acidcatalyzed sol-gel method has high specific surface area (i.e., $454 \mathrm{~m}^{2} / \mathrm{g}$ ) and great porosity (i.e., 66.9\%) with pore size of less than $5 \mu \mathrm{m}$. Relatively great adsorption of HA by the TCNSP composite can be explained by its high surface area and high removal efficiency ( $\geq 95 \%)$ of HA under photocatalysis indicate significant synergistic effects by coupling adsorption and photocatalytic reaction of TCNSP composite. As the initial concentration of HA increased, the degradation rate $\left(K_{\mathrm{app}}\right)$ decreased since the pores of the TCNSP composite surface gradually reached HA saturation, and the photons generated from UV light were intercepted by the HA molecules in aqueous solution. Since the increased loading amount of TCNSP composite enhanced the number of active sites, $K_{\text {app }}$ values increased with the optimum loading amount of TCNSP composite. A faster and greater degradation of $\mathrm{HA}$ in the presence of $\mathrm{TiO}_{2}$ combined with UVA or UVC irradiation was observed, compared to reactions with only sole UVA or UVC irradiation. As $\mathrm{pH}$ values increased, HA removal efficiency decreased due to increasing electrostatic repulsion between HA and TCNSP composite. After several runs, both adsorption and photocatalytic ability of NZLC were constant so removal efficiency of HA was kept at high level. Finally, higher HA removal efficiencies were obtained with acidic condition, longer reaction time, and appropriated loading amount of TCNSP based on the response surface methodology. A field study is in progress using prepared TCNSP composite combined with UVC to remove HA from surface water.

\section{Competing Interests}

The authors declare that they have no competing interests.

\section{Acknowledgments}

This study was partially supported by the Korea Ministry of Environment as "The GAIA Project (no. 2012000550005)" and by the "Newly Appointed Professor Research Fund" of Hanbat National University in 2014.

\section{References}

[1] F. G. Stevenson, Humus Chemistry: Genesis, Composition, Reactions, John Wiley \& Sons, New York, NY, USA, 1994.

[2] E. Loffredo and N. Senesi, "The role of humic substances in the fate of anthropogenic organic pollutants in soil with emphasis on endocrine disruptor compounds," in Soil and Water Pollution Monitoring, Protection and Remediation, pp. 69-92, Springer, 2006.

[3] C. S. André and M. Khraisheh, "Removal of humic substances from drinking water using GAC and iron-coated adsorbents: consideration of two kinetic models and the influence of mixing," Environmental Engineering Science, vol. 26, no. 1, pp. 235-243, 2009.

[4] X. Wang, Z. Wu, Y. Wang et al., "Adsorption-photodegradation of humic acid in water by using $\mathrm{ZnO}$ coupled $\mathrm{TiO}_{2}$ /bamboo charcoal under visible light irradiation," Journal of Hazardous Materials, vol. 262, pp. 16-24, 2013.

[5] H. Fang, D. D. Sun, M. Wu, W. Phay, and J. H. Tay, "Removal of humic acid foulant from ultrafiltration membrane surface using photocatalytic oxidation process," Water Science and Technology, vol. 51, no. 6-7, pp. 373-380, 2005.

[6] J. K. Kim, J. Alajmy, A. C. Borges, J. C. Joo, H. Ahn, and L. C. Campos, "Degradation of humic acid by photocatalytic reaction using nano-sized $\mathrm{ZnO}$ /laponite composite (NZLC)," Water, Air, and Soil Pollution, vol. 224, no. 11, article 1749, 2013.

[7] F. Zhang, J. Zhao, T. Shen, H. Hidaka, E. Pelizzetti, and N. Serpone, " $\mathrm{TiO}_{2}$-assisted photodegradation of dye pollutants 
II. Adsorption and degradation kinetics of eosin in $\mathrm{TiO}_{2}$ dispersions under visible light irradiation," Applied Catalysis B: Environmental, vol. 15, no. 1-2, pp. 147-156, 1998.

[8] M. Khraisheh, J. Kim, L. Campos, A. H. Al-Muhtaseb, G. M. Walker, and M. Alghouti, "Removal of carbamazepine from water by a novel $\mathrm{TiO}_{2}$-coconut shell powder/UV process: composite preparation and photocatalytic activity," Environmental Engineering Science, vol. 30, no. 9, pp. 515-526, 2013.

[9] F. C. Doria, A. C. Borges, J. K. Kim, A. Nathan, J. C. Joo, and L. C. Campos, "Removal of metaldehyde through photocatalytic reactions using nano-sized zinc oxide composites," Water, Air, and Soil Pollution, vol. 224, no. 2, article 1434, 2013.

[10] J. C. Joo, C. H. Ahn, D. G. Jang et al., "Photocatalytic degradation of trichloroethylene in aqueous phase using nanoZNO/Laponite composites," Journal of Hazardous Materials, vol. 263, pp. 569-574, 2013.

[11] Y. Ma, X. Wang, Y. Jia, X. Chen, H. Han, and C. Li, “Titanium dioxide-based nanomaterials for photocatalytic fuel generations," Chemical Reviews, vol. 114, no. 19, pp. 9987-10043, 2014.

[12] R. H. Myers and D. C. Montgomery, Response Surface Methodology: Process and Product Optimization Using Designed Experiments, John Wiley \& Sons, New York, NY, USA, 2nd edition, 2002.

[13] Y. Sudaryanto, S. B. Hartono, W. Irawaty, H. Hindarso, and S. Ismadji, "High surface area activated carbon prepared from cassava peel by chemical activation," Bioresource Technology, vol. 97, no. 5, pp. 734-739, 2006.

[14] Y. Li, S. Zhang, Q. Yu, and W. Yin, “The effects of activated carbon supports on the structure and properties of $\mathrm{TiO}_{2}$ nanoparticles prepared by a sol-gel method," Applied Surface Science, vol. 253, no. 23, pp. 9254-9258, 2007.

[15] W. Li, K. Yang, J. Peng, L. Zhang, S. Guo, and H. Xia, "Effects of carbonization temperatures on characteristics of porosity in coconut shell chars and activated carbons derived from carbonized coconut shell chars," Industrial Crops and Products, vol. 28, no. 2, pp. 190-198, 2008.

[16] X. Van Doorslaer, K. Demeestere, P. M. Heynderickx et al., "Heterogeneous photocatalysis of moxifloxacin: identification of degradation products and determination of residual antibacterial activity," Applied Catalysis B: Environmental, vol. 138-139, pp. 333-341, 2013.

[17] A. A. M. Daifullah, B. S. Girgis, and H. M. H. Gad, "A study of the factors affecting the removal of humic acid by activated carbon prepared from biomass material," Colloids and Surfaces A: Physicochemical and Engineering Aspects, vol. 235, no. 1-3, pp. 1-10, 2004.

[18] M. M. Haque and M. Muneer, "Photodegradation of norfloxacin in aqueous suspensions of titanium dioxide," Journal of Hazardous Materials, vol. 145, no. 1-2, pp. 51-57, 2007.

[19] L. Yang, L. E. Yu, and M. B. Ray, "Degradation of paracetamol in aqueous solutions by $\mathrm{TiO}_{2}$ photocatalysis," Water Research, vol. 42, no. 13, pp. 3480-3488, 2008.

[20] C. A. Coles and R. N. Yong, "Humic acid preparation, properties and interactions with metals lead and cadmium," Engineering Geology, vol. 85, no. 1-2, pp. 26-32, 2006. 

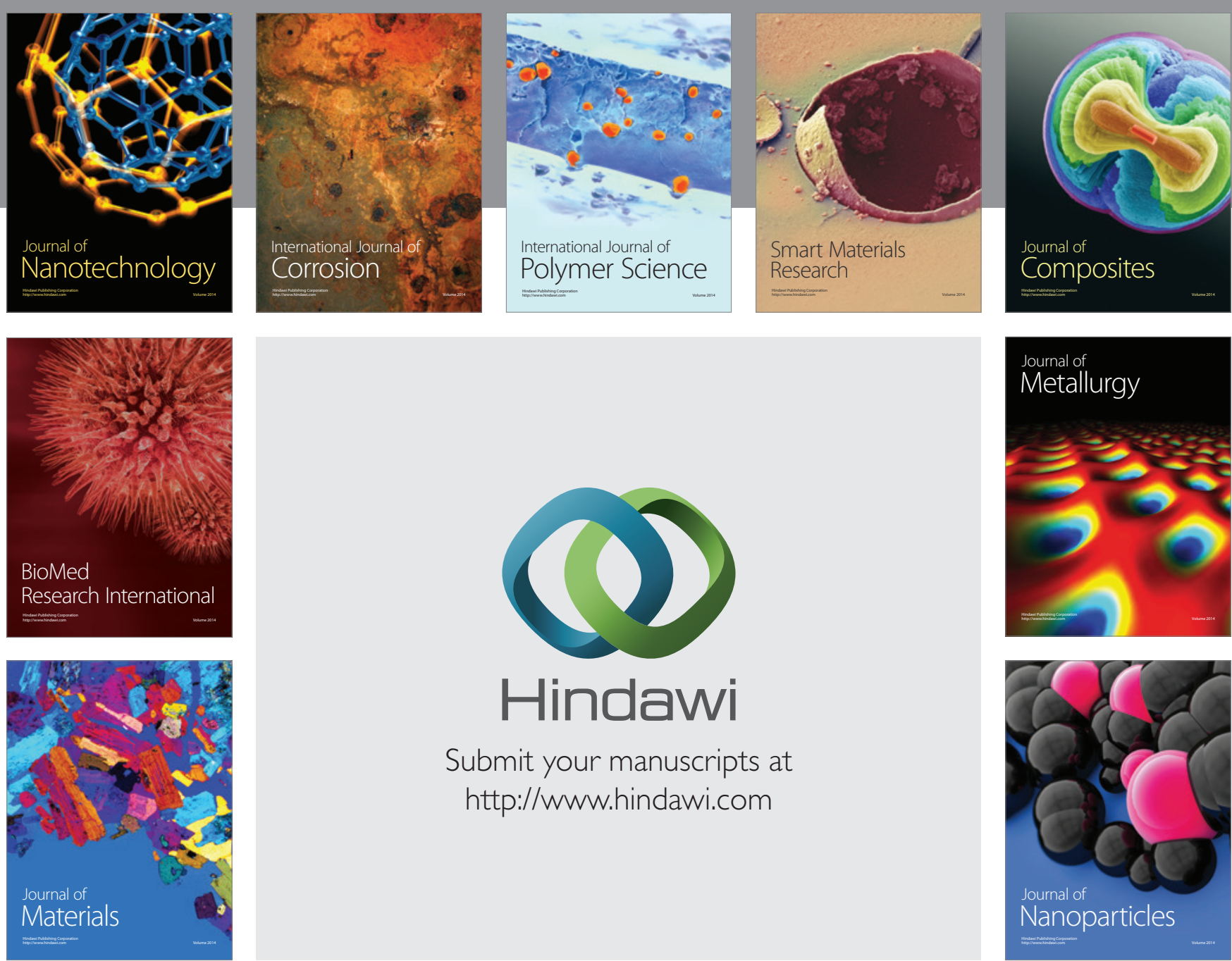

\section{Hindawi}

Submit your manuscripts at

http://www.hindawi.com

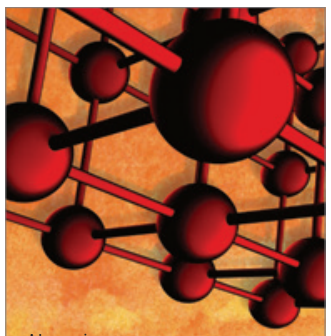

Materials Science and Engineering
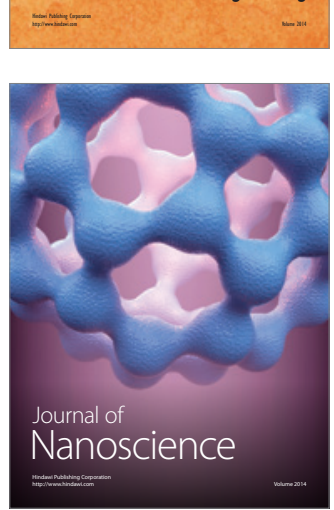
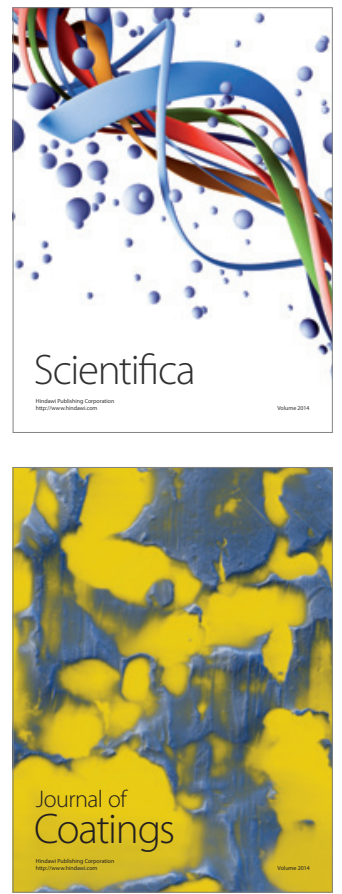
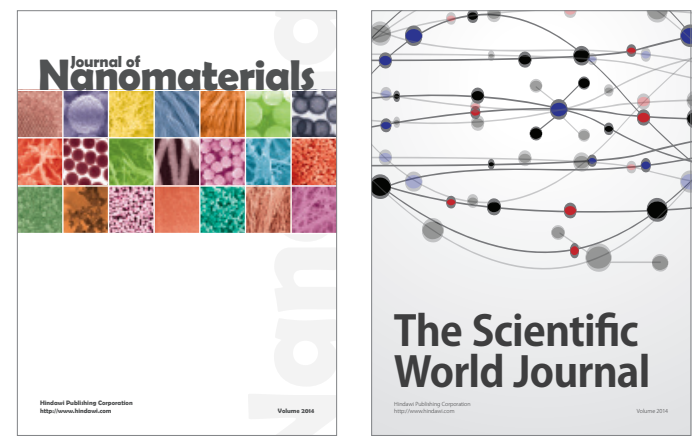

The Scientific World Journal
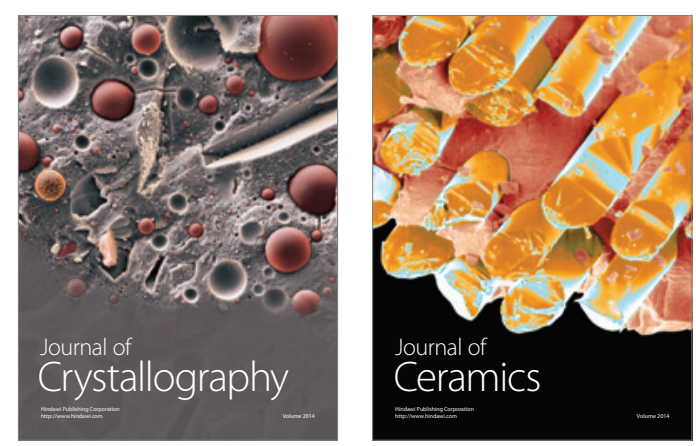
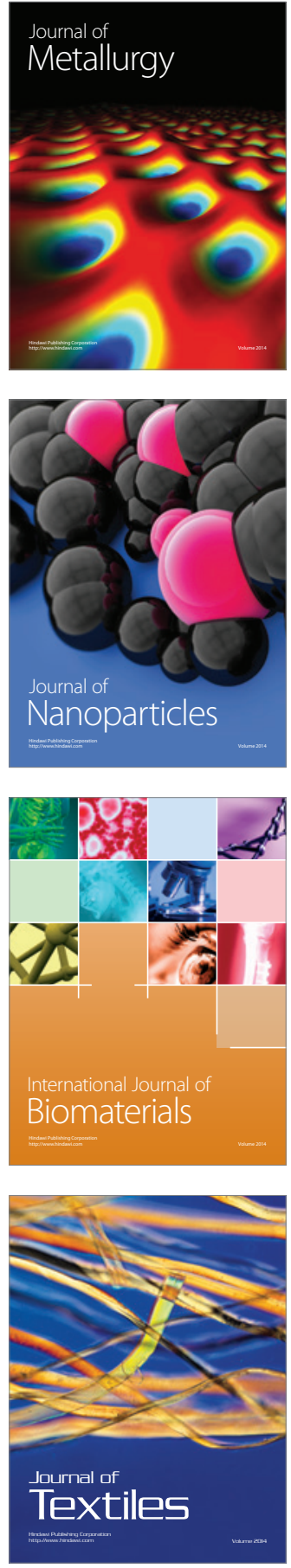